\title{
El Lenguaje y la Función Social de la Universidad $^{\star}$
}

por Alberto Escobar

Die Sprache ist das bildende Organ des Gedanken.

W. v. Humboldt.

* La historia de la Linguística está ligada estrechamente al desarrollo del pensamiento occidental. Por ende, meditar sobre el aspecto teórico o la proyección práctica del estudio del lenguaje, significa adherirse a una preocupación fundamental del ser humano, homo symbolicus por excelencia, y participar activamente en un coloquio ininterrumpido, en una constante inquieud del área espiritual en que vivimos. En virtud de ese paralelismo, las ideas que, en relación con el lenguaje, se ofrecen al hombre con-

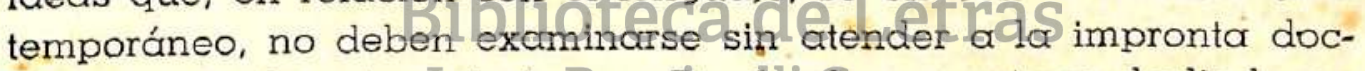
trinaria que les sirve degbasel CDe dondeonupeprimer deslinde en el tema que nos ocupa, resalta la correspondencia existente entre toda interpretación concreta del hecho lingüístico, $\mathrm{y}$, una teoría previa acerca del lenguaje, sobre la que ésa se apoya. Entiéndase que no subordinamos la Lingüística a la Filosofía, pero sí que tomamos conciencia de su interrelación.

Es sabido que la Lingüística como disciplina científica aparece en el siglo XIX, y que lo especulado anteriormente sobre la materia se conoce con el nombre de Lingüística Empírica; no porque los juicios acumulados en dicho período carezcan siempre de verdad, sino, más bien, por la falta de rigor sistemático, por la ausencia de método $\mathrm{y}$ finclidad reconocidos. El tema predominante en la Lingüística Empírica no fue otro que el origen del

* Discurso de Orden pronunciado en la Facultad de Letras de la Universidad Nacional Mayor de San Marcos, en la ceremonia de apertura del año académico de 1959. 
lenguaje. Y en esta meditación debe verse el meollo de un extenso y fecundo reflexionar, pues a ella conduce el debate iniciado por los presocráticos acerca de la lengua en tanto physis o en tanto nómos; y en ella se engarzan los planteamientos de Platón y Aristóteles, cuyo influjo subsiste a través de la latinidad, prolongándose en el medioevo. Fue así como el realismo neoplatónico y el realismo tomistá reprodujeron la competencia entre la consideración lógica y la consideración formal del lenguaje.

¿Es el lenguaje obra dependiente de una necesidad natural (physis), externa a los hombres; o es invención humana (nómos)? ¿Es producto logrado, completo (érgon); o es creación, potencia (enérgeia)? He ahí la alternativa, el dilema angustioso del pensamiento griego, en cuya antigüedad no sólo rastreamos el antecedente histórico, sino más, mucho más : el rasgo esencial que preside con su proyección psicológica y lógica dos mil años de historia lingüística. El primer planteamiento, fundado en la tesis platónica, indaga por el vinculo natural que une la palabra con la cosa representada; mientras el segundo apoyado en las ideas aristotélicas, distingue entre pensamiento y expresión, y separándolos, prueba la docilidad de ésta frente a aquél.

La corriente psicológica cultivó la etimología, conforme lo atestigua su uso desde Platón hasta San Isidoro de Sevilla y los forjadores de la l" "Gromática Harmónica"tien los siglos XVII y XVIII. El influjo de Aristóteles se percibe, en cambio, a través de la orientación logicista, en fa concepcion gramátical de los estoi$\mathrm{cos}$, en la especulativa de los escolásticos, en la Gramática General del siglo XVI y en el Iluminismo. Admirable proceso que el hablante de nuestros días no puede contemplar sin asombro; incesante y hermoso quehacer con un fenómeno como el lenguaje, tan entrañado en el ser del hombre, y sin embargo, por lo mismo, irrelevante para el hombre común.

La introducción de la escritura en Grecia dio origen a una actividad práctica. En la tekhné grammatiké de los griegos ( $y$ en la ulterior Ass Grammatica de los romanos), predomina el concepto de tekhné (Ars), es decir, la noción de habilidad, de oficio para ejecutar una tarea; porque, con la introducción de la escritura alfabética, y la descomposición de la palabra en sonidos, se hizo necesaria la tekhné, en cuanto procedimiento auxiliar. De ella, más adelante, derivará la Gramática Normativa, que en su origen estuvo limitada exclusivamente a la fonética, así como ésta formaba 
parte de la música. Por otro lado, la relación entre escritura y gramática es evidente, pues el nombre de ésta deriva de Gramma, letra. Y sólo con el trascurso del tiempo la Escuela de Alejandría abordará "cuestiones gramaticales", entendiendo con ese nombre la clasificación de fenómenos impuesta por la tendencia analogista que animó a dicha escuela.

En Roma, en cambio, la suerte de la Tekhné tuvo un desarrollo más veloz en virtud de causas especiales. En Roma, el latín aún no había logrado unidad comparable con la alcanzada por la lengua general, por la koiné griega. La iniciación literaria y la expansión oficial tropezaban con una lengua todavía vacilante en el uso, con variedad de formas alternativas. La necesidad de imponer disciplina en la lengua, en una época en la que Roma asumía el papel conductor de una cultura homogénea, influyó en la acogida de las ideas helénicas, y en la activa participación de los romanos en el quehacer gramatical. Fruto de esa preocupación será la admirable "pureza" de la lengua ciceroniana, formada en la norma de la latinitas, sobre la cual Varrón reseñaba: "latinitas est incorrupte loquendi observatio secundum Romanam linguam".

El Humanismo, con su retorno al espiritu clásico, favoreció el apogeo de la gramática con miras a la consecución de la elegancia latina. Perobés más qativg lè preocupación gramatical cuando, del fondo común de la Romania insurgen los romances a la categoría de lenguás nadionfles. IS antes se había percibido la urgencia de estabilizar la escritura del latín, afligida por el efecto diversificador de los Vulgares, de cada rustica romana lingua; ahora, aquellos Vulgares, convertidos en lenguas nacionales, demandaban el reconocimiento de su unidad, con el objeto de distinguirse precisamente del latín, que por entonces sólo era accesible a los letrados. La afirmación de las lenguas neolatinas y su influencia en el horizonte histórico, tan claramente apreciable a través del fenómeno lingüístico, constituye -como lo hace notar Terracini- una revolución extraordinaria en el orden de la cultura y de la sociedad. Muy significativo es en este respecto el caso del español, si se piensa en la importancia de la abra de Nebrija y en las circunstancias que rodearon su aparición; porque es necesario comprender, como lo destaca acertadamente Lapesa, la trascendencia histórico-social del acontecimiento: "En agosto de 1492, meses después de la rendición de Grana- 
da y estando en viaje las naves de Colón, salía de la imprenta la Gramática castellana de Antonio de Nebrija. El concepto de "artificio" o "arte", esto es, regulación gramatical, estaba reservado a la enseñanza de las lenguas cultas, como el latín y el griego: era una novedad aplicarlo a la lengua vulgar...." No se olvide tampoco que para Nebrija "siempre la lengua fue compañera del imperio", por donde ya descubrirá el autor su propósito político y práctico de codificar y normalizar la lengua a fin de evitar su decadencia. Mas sería injusto desconocer en esta obra, la primera en su género para una lengua moderna, que, pese a nutrirse de las teorías de los gramáticos latinos, consigue sentar algunos postulados exactos acerca de la naturaleza de la lengua española.

Intentos de gramáticas lógicas, filosóficas, generales, harmónicas, inspiradas estas últimas en el deseo de hallar la comunidad etimológica que relacionara a una serie de lenguas por esa época descubiertas, abundaron hastonel siglo XVIII. En todas subsistía el concepto primitivo que dio origen a la Tekhné Grammatiké, pero ya sin idea clara de los límites reconocidos por ésa; $\mathrm{y}$, asímismo, en todas se trasluce la huella del criterio latino fundamentalmente interesado en la regularidad de los hechos linguísticos.

Desde un punto de vista moderno, la actitud clásica frente a los hechos linguisticos asume ue carácter anconfundible merced

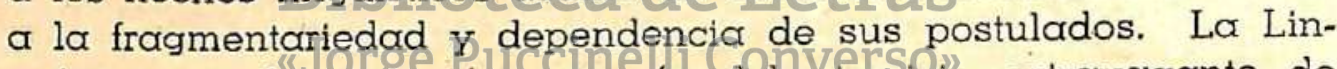
guística empírica sirvio, a través dell ejercicio extravagante de etimologías, anomalías y analogías, como piedra de toque de una inquietud más amplia centrada en la teoría del conocimiento; $\mathrm{O}$, conectada como estaba al devenir socio-político comunal, poseído por su impetuosa exigencia de actualidad; derivó en forma paulatina entre los griegos, y de modo más decidido a partir de los romanos, hacia un menester de finalidad práctica: la Tekhné Grammatiké o Ars Grammatica. Y por tanto, no se llegó a superar el plano de la sistemática empírica o de la tarea normativa, situación que es explicable, a juicio de Pagliaro, si se tiene en cuenta la intensidad con que los antiguos percibieron la historicidad del hecho literario, y el valor que concedieron a la escritura. Diferente es en cambio el carácter de la gramática medieval, en la que priva de manera creciente la consideración lógica de la lengua sobre la consideración histórica. Sin embargo, a la linguíística empírica hay que reconocerle no sólo haber tendido los ca- 
rriles por los que se orientó el estudio del lenguaje, sino además, una serie de apreciaciones felices: el concepto del latín vulgar. el parentesco de las lenguas semíticas, el origen común de las germánicas, y colecciones de vocablos de lenguas asiáticas y americanas recogidas por Marco Polo, Pigafetta $\circ$ Alexander von Humboldt, o por un ejército de misioneros anónimos. Pero era imprescindible que apareciera una concepción diversa de la historia de la civilización y del espíritu humano; era imprescindible que la intuición genial de Vico (raíz poética del lenguaje) fuera aprovechada por el romanticismo alemán, y confluyera en la linguística por intervención de Herder, de Friedrich Schlegel y, con gesto definitivo, por Wilhelm von Humboldt. En este punto nacen los fundamentos de la Lingüística Científica, de la observación rigurosa y metódica del fenómeno lingüístico. Sólo ahora se explica la oposición entre la uniformidad del espíritu humaho y la variedad de las lenguas; por primera vez se comprende la antinomia entre el sujeto que crea su expresión, y la lengua que se ofrece como conjunto a la libertad, a la posibilidad expresiva. Con Humboldt se delimita la actividad del individuo, de una parte, y la lengua como producto histórico recibido por el sujeto parlante; se distingue entre el lenguaje como facultad natural, y la lengua nacional con su específica "forma interior"; de ese modo surge con nitidez la concepción del lenguaje como continuo recrear, como enérgeia, y el problema del origen del lenguajes tronsformacen el problema de su naturaleza. Hej ghí la tarea que asumela Linguística Científicor.

La incorporación del sánscrito en el ámbito de las disquisiciones lingüísticas y su cotejo con el griego y el latín, colocaron a nuestra disciplina ante un nuevo tipo de labor: die Vergleichende Sprachwissenschaft, o ciencia comparada del lenguaje, la cual se propuso descubrir la naturaleza de la lengua por el procedimiento de la confrontación estructural entre las principales lenguas conocidas. Así fue fundada, sobre bases sólidas, la Lingüística Indoeuropea. El comparatismo arrasó con la fantasía etimológica y el patrón lexical, y sancionó, en cambio un método nuevo, sustentado en el análisis de las estructuras interiores, en la coincidencia o discordancia de dichas estructuras. En la tarea de confrontar lenguas antiguas, tal como la entendían Schlegel y Bopp, la lingüística se inscribió en una perspectiva fundamentalmente histórica y se hicieron evidentes sus contactos con la etno- 
grafía, el folklore, la poesía, la historia de la cultura, etc. Fue tan notable el impulso adquirido por los estudios comparativos y por la gramática histórica, que en muy pocos años la joven ciencia había acumulado un cuantioso fondo de conocimientos sobre el lenguaje humano. Las experiencias ganadas con el estudio del Indoeuropeo, germinaron luego en la Lingüística Germánica y en la Lingüística Románica, contribuyendo ésta muy pronto al progreso de las otras disciplinas, gracias a la facilidad de disponer de la lengua base: latín, y de las lenguas evolucionadas : las neolatinas.

Con la lingüística científica se adoptó el concepto de lengua como "forma orgánica", en el cual se sustentó de un lado, el método de la comparación, y más adelante, la idea de evolución. El vertiginoso desarrollo de la ciencia, en su progreso hacia el siglo $\mathrm{XX}$, se nutrió por cierto de otras orientaciones : la naturalista, de Schleicher; la neogramática, de Hermann Paul; la sociologista, de la Escuela de Ginebra. El Curso de Lingüística General de Ferdinand de Saussure, con el planteamiento eminentemente social del lenguaje, cierra una rica parábola iniciada por el comparatismo, y constituye la piedra capital sobre la que se apoyarán las direcciones más notables de la Lingüística Contemporánea. En la obra del Maestro de Ginebra debe verse la síntesis de cuanto valioso y verdaderro había logrado la ciencia en su corto desarro$1 l o y$ en sus diversas etapas. Por eso, no solo lo continúan sus discípulos de "Ginebrâ y ydela Escuelandzepafis", sino que a él se remiten y en su tesis se complementan las ideas de quienes como Croce, Vossler, Spitzer, Wartburg, Terracini, Pagliaro, Alonso, etc., pertenecen a la tendencia espiritualista de la lingüística actual, por muchos conceptos adversaria de la tesis saussureana. Asímismo, los puntos doctrinarios de Trubetzkoy y de las Escuelas de Praga y Copenhague tienen su base inicial en las ideas del Maestro ginebrino.

Para la corriente espiritualista, conocida también con el nombre de Escuela de Munich, a la que se haya adherido quien habla, y de la que el Dr. Jiménez Borja fue el primer propugnador entre nosotros, allá por el año 1928, el problema de la naturaleza del lenguaje subsiste. Pero ya no en los términos exclusivos de "forma orgánica", tal como fuera planteado hasta las primeras décadas del siglo actual. Al retomar una noble tradición que comienza en Vico, continúa en Humboldt y prosigue con Croce y las 
tendencias germánica e italiana, el idealismo lingüístico asume el valioso aporte de las corrientes decimonónicas, pero establece un nuevo ordenamiento, dentro del cual, el mecanismo lingüístico queda sometido al papel rector del espíritu individual del hablante. Merced a esta actitud, la lengua y la cultura se reflejan e iluminan mutuamente; la lengua aparece como una de las formas de la cultura, y la historia de la lengua se convierte en un modo particular de la historia, como juego dialéctico entre lo subjetivo y lo objetivo, entre la creación y la herencia cultural.

Si algo caracteriza a la corriente idealista, es sin lugar a dudas, la función que ella asigna al sujeto parlante; es el haber concluido con el mito de la lengua como exclusivo hecho social, como sistema externo y permanente. El idealismo presupone un incesante cambio de influencias entre el sujeto y la lengua comunitaria; la historia de la lengua vista así es producción y producto. Pierde todo sentido la oposición entre hablante y comunidad; desaparece la idea romántica del sujeto/recluido por el cerco lingüístico, en pugna con las leyes inflexibles del idioma. Y en remplazo, propone el idealismo atender al sujeto en el acto de hablar, es decir, en el instante en que interpreta, según su personalidad, la tradición lingüística dentro de la que vive, $y$, merced a ese acto, concreta una forma cultural. Tarea de la lingüística es, por ende, comprender el modo cómo un parlante, o un grupo de parlantes, en una época, en un lugar, enouna circunstanciatinterpretan la tradición lingüística de «un determinadg; comunidad Bien claro queda que, también en este nuevo periodo de la meditación sobre el lenguaje, existe una equivalencia con el sentido filosófico de la época. Ia lingüística, como la filosofía contemporánea, se propone descubrir la huella del hombre en el concierto de la cultura, y ambas son, en cierto modo, expresiones de una antropología, formas de vivir el hưmanismo.

El breve recuento de la evolución operada en el modo de observar el lenguaje, y de los postulados enunciados en cada período, habrá puesto de relieve un principio evidente, pues, como insiste Devoto: "Una "teoría de la lengua" es, no ya la "culminación de la actividad empírica de los lingüistas" sino su punto de partida". Y este punto de partida es sustantivo en nuestro propósito, si advertimos que él influye no sólo en el objeto de la ciencia, sino además en su proyección práctica; recuérdese por ejemplo la idea griega de la lengua y la aplicación etimológica; la tesis 
analogista y el florecimiento de la gramática latina; el concepto evolutivo y el apogeo de las leyes fonéticas. Por tanto, antes de proseguir, averigüemos por la idea, por la imagen, del lenguaje en la lingüística contemporánea.

Ya tuvimos oportunidad de decir que la lingüística contemporánea se asienta en la obra de Ferdinand de Saussure. Para este autor, definir el objeto y el método de la ciencia lingüística constituyó una exigencia previa y fundamental. De Saussure deslindó algunos conceptos indispensables para comprender la imagen de nuestro objeto de estudio, a saber: El lenguaje humano, que comprende todas las formas de expresión, pero como éste, a los ojos del estudioso positivista aparecía "como un montón confuso de cosas heterogéneas y sin trabazón" (sílabas, sonidos, sistema, lado individual, convención, renovación, etc.), optó de Saussure por introducir dentro del lenguaje, una pareja de conceptos: La Lengua y el Habla, que encarnan el lado social y el lado individual del lenguaje. He aquí suś palabras: "Tomado en su conjunto el lenguaje es multiforme y heteróclito; a caballo en diferentes dominios, a la vez físico, fisiológico y psíquico, pertenece además al dominio individual y al dominio social; no se deja clasificar en ninguna de las categorías de los hechos humanos, porque no se sabe como desembrollar su unidad". En cambio "la lengua (sistema de signos propio de un grupō social) no es más que una determinada parte del lenguaje, aunque esencial. Es a la vez un producto social de la faculfad del lengudjer'y Qun conjunto de convenciones necesarias adoptadas por el cuerpo social para permitir el ejercicio de esa facultad en los individuos". De Saussure pensó que lengua y habla eran entidades independientes, autónomas, si bien reconocía que eran como las dos caras de una medalla; pero, para el estudio lingüístico, él no admitía como objeto de investigación sino a la lengua, que a su entender "hace la unidad del lenguaje". Mientras el habla, en cambio, es el acto momentáneo de hablar, mediante el cual un individuo recorre el sistema de la lengua y lo utiliza a fin de expresarse. Ahora bien, como lo ha señalado Alonso, el pensamiento de Saussure funcionaba a base de oposiciones; la antinomia constituía para él una exigencia metodológica; pero además, uno de los términos de la oposición quedaba sometido al otro, y prácticamente descartado del campo científico. Igual ocurre en el contraste entre la Diacronía y la Sincronía, entre la lingüística diacrónica y la sincrónica: "la oposi- 
ción entre los dos puntos de vista -diacrónico y sincrónico-, escribe de Saussure, es absoluta y no tolera componendas". Este juego de binomios: lengua-habla, diacronía-sincronía, combinado con el principio de la objetividad de la lengua, en tanto sistema de signos propio de un grupo social, refleja claramente el concepto que de Saussure poseía de la Lengua. En él debe advertirse asímismo el predominio de una visión sistemática y antihistórica, merced a la cual en el conjunto de los fenómenos lingüísticos se observa "más la unidad que la multiplicidad, más la tendencia a la inercia que al movimiento, más las fuerzas y las líneas generales que el desarrollo de la individualidad del hecho lingüístico". En ello es evidente un cambio de perspectiva científica, pues se deja a un lado la contemplación de lo fragmentario, de los datos aislados, de los hechos minúsculos, esencial a la investigación positivista, y se orienta nuestra disciplina hacia el descubrimiento de una unidad ideal, hacia lo constante del lenguaje.

Pero el mérito mayor del cuerpo doctrinario del Maestro de Ginebra es su insólita fecundidad. Tanto Bally como Sechehaye han profundizado las ideas de Saussure, investigando en el aspecto afectivo y psicológico de la lengua, para llegar a una concepción menos rígida que la del ginebrino, y con más plena conciencia del factor individual en el hecho idiomático. De este modo, si se tiene en cuenta eBinflujodela teoría croceang expuesta en la Estetica come Scienza dell' espressione e Linguistica Generale, según la cual el lenguaje es un acto espirifual y creativo, y que en virtud de la identidad de intuición y expresión, Estética y Lingüística se funden en una sola actividad, llegaremos a la nueva teoría en curso. Aparentemente entre las tesis de Croce y de Saussure hay un abismo; sin embargo, en virtud del esfuerzo de Vossler, y las contribuciones de Wartburg y Devoto, la lingüística contemporánea ha delineado una imagen rotunda de la esencia lingüística. La ciencia del lenguaje se ha goznado definitivamente sobre la acción del espíritu individual, tal como lo intuyeron Vico y Humboldt, pero no se ha detenido en la contemplación exclusiva de la originalidad del individuo, ni de la libertad creadona, como lo proponía Croce, porque este exclusivismo la condenaba a una inevitable esterilidad científica. Vossler, Wartburg y Devoto han desechado tanto la visión unilateral de Saussure (la lengua, el sistema objetivo), como la igualmente unilateral de Croce, (el acto creador, el hecho estético)، y han enseñado con profunda visión 
del problema, que el lenguaje tiene una estructura polar y móvil, reconociéndole, tanto valor al aspecto emocional e individual del habla, como al lógico y social de la lengua. En este camino se descubre que el objeto de la ciencia es la complejidad del mecanismo lingüístico que rechazaba de Saussure, que lengua y habla, diacronía, sincronía no se ejercen de manera inflexible, porque si la lingüística es una disciplina del espíritu, le toca "buscar en el lenguaje aquellos aspectos más cargados de espíritu". Por tanto, el objeto de la lingüústica consiste "en el ir venir de un polo a otro, que es un perpetuo movimiento en el cual desde el primer instante actúan los dos polos, pues la creación individual nace ya orientada por y hacia las condiciones del sistema espectante, y el sistema de la lengua no tiene ni posible funcionamiento, ni posible historia más que gracias a la intervención de los individuos concretos que la hablan".

Sencilla y compleja realidad la del lenguaje. De ahí proviene, la indiferencia con que el hombre común reacciona ante los temas propios de nuestra disciplina, pero asímismo de ahí procede gran parte de las confusiones, igualmente dañinas, que se han perpetuado acerca de la realidad de la lengua, de su función en la colectividad, y del método de su enseñanza. Sin una justa y cristalina premisa teórica, será muy difícil valorar en su legítima magnitud temas lapasionantes que se nutrensen la relación entre individuo y sociedad, sspíritu y cultura, creación y evolución, categorías psicologicas y gramaticales, estilistica y sintaxis, originalidad y tradición, libertad y determinismo, etc., que invitan a meditar a todo aquel que se ocupa en cuestiones del lenguaje. Y no menos fecundo ni menos provechoso es comprobar de qué modo se construye el pensamiento científico; de qué modo se integra y perfecciona nuestro concepto del lenguaje, aparte de toda tentación de congelamiento, aparte del explicable deseo -en los discípulos- de convertir en texto sagrado la obra del maestro.

En los recientes exámenes de admisión a la Universidad, el que habla tuvo el honor de ser miembro del, Jurado B, Sección Pre-Derecho, y de calificar las pruebas de castellano y literatura. Sin acudir a datos estadísticos, quisiera subrayar el desconcierto de los examinadores al advertir el escaso dominio idiomático mostrado por los postulantes. No me refiero sólo a las faltas ortográficas, errores de concepto o pobreza de vocabulario, de por sí alarmantes, sino más bien a la carencia de habilidad para redactar, 
para hilvanar ideas, para asociar pensamientos y coordinarlos aceptablemente. Ya sea que, quienes aquí me escuchan, participen de la tesis que distingue entre pensamiento y lenguaje, o de la que los fusiona, para el objeto que esta reflexión persigue basta con reconocer que, en todo caso, el pensamiento se manifiesta a través del lenguaje, y que tan grave deficiencia en el uso del idioma, no puede sino descubrir ausencia del hábito de pensar. Si partimos de esta comprobación, debemos luego preguntarnos, cuál es el sistema de estudio del lenguaje a que han estado sometidos aquellos alumnos, y por qué razones tan escaso fruto. No es mi propósito poner en tela de juicio la eficiencia de los profesores de lengua y literatura, ni echar la más leve sombra sobre la capacidad de los jóvenes estudiantes. Por el contrario, la seguridad de la eficiencia y vocación de los primeros, y de la aptitud normal de los segundos, me incita a meditar en torno de las verdaderas causas de tan delicado asunto.

$\mathrm{Si}$ el estudiante peruano es instruído en cuestiones del lenguaje a lo largo de la Enseñanza Primaria y Secundaria, debería lógicamente, llegar a la Universidad con suficiente dominio de su lengua materna. Mas no ocurre así, bien lo sabemos, en la enorme mayoría de los casos. Incluso, hay que decirlo con toda hidalguía, tampoco es satisfactorio el nivel de conocimientos que, acerca de su propiojaiomáa posee el estudiante de la sección doctoral de nuestra Universidad. ¿A que razones obedece esta crisis?

En principio, "Ja enseñanza de la lengua en las escuelas y colegios peruanos está orientada por un criterio eminentemente gramatical. También es gramática normativa lo que se ofrece en la Facultad. Hace unos instantes recordamos el origen y sentido de la gramática: finalidad práctica para disciplinar la escritura. Eso que en nuestros manuales es: arte de hablar y escribir correctamente una lengua, pero habiendo desaparecido hoy toda idea del valor semántico original con que fue usada la palabra arte, que vimos ya, no era sino artificio, artesanía. La Gramática surgió, ya lo dijimos, nutrida por una concepción del lenguaje como érgon, como entidad estable, permanente; cuando la idea del lenguaje era dominada por el concepto de su. realidad fija, lograda, concluída. La Gramática era un conjunto de recursos prácticos que auxiliabon de la misma manera que lo hacía la retórica, hoy caída en desuso y remplazada por la estilística. Pero la gramática, en virtud del refugio que le dispensó el interés 
histórico, se ha prolongado hasta los días nuestros con un carácter eminentemente normativo y colítico. Si nos colocamos en un plano independiente de influjos doctrinarios, y aceptamos que el mantenimiento de la enseñanza gramatical tenía como propósito enseñar a escribir, a pensar, a descubrir los elementos básicos de la vida de relación, y a fomentar en el estudiante, de esa manera, el descubrimiento de un aspecto esencial de su condición humana: hombre que posee y cultiva una lengua, tenemos pleno derecho de averiguar, acto seguido, si, con la enseñanza gramatical impartida en la escuela peruana, se alcanzan semejantes objetivos. Pienso que la respuesta es unánime: no, no se alcanzan.

Con frecuencia se suele escuchar que desde hace cincuenta años vivimos un proceso que conduce en forma paulatina, pero no menos evidente, a un empobrecimiento del dominio lingüístico, a una mengua apreciable de la facultad de escribir y conversar, de leer y comprender. Sin duda esto es cierto en gran parte. No puede ocultarse qué en ello influye el descrédito en que ha caído el ideal del erudito en beneficio del especialista, del hombre culto en favor del técnico; el ritmo de la vida contemporánea ha empequeñecido, a los ojos de los más, la importancia formativa de la literatura, la historia o la filosofía. Pero aparte de este proceso de vastas implicancias sociales, hay razones que explican, de compärarse ja enseñanza actua glo atrás, el aflíctivo estado en que nos encontramos. Al desaparecer el aprendizajej de las qiengudisCáásicaş coesó una invalorable fuente de conocimiento lingüístico, que provenía en parte, de la relación histórica entre el latín y el español, y en parte, porque con los clásicos se trabaja sobre textos, sobre lenguaje en acto, sorprendiendo la actividad de la lengua en la realidad que después abstrae la gramática. Por eso, aunque parezca paradójico, quien aprendió latín o griego debía conocer mejor su lengua, e incluso la gramática, que aquel que sólo estudió español. Y aquí otra paradoja: las lenguas muertas se aprendieron en su realidad viva, mientras el español, lengua viva, se aprende en un cuadro de abstracciones que bien podrían ser llamadas muertas.

Pero tratándose de un hecho tan reciente como el que dio origen a esta reflexión, debemos hurgar causas más próximas. La vida social de comienzos de siglo giraba en gran parte, en torno de varios ejes, que eran no obstante idénticos: la sobreme- 
sa, la charla en el hogar, en el paseo, en el café, la lectura en coro, los juegos de sociedad fundados en la participación activa de los concurrentes, etc. No se requiere abundar en argumentos, si frente a la enumeración onterior indicamos: el cinematógrafo, diversión muda; la televisión, entretenimiento mudo; y el remplazo de la lectura formativa o de aventuras por la simplicidad deformadora de las historietas y los chistes. Pero hay otra razón, e indisculpable por su gravedad. Hace unos años, el Ministerio de Educación pretendió asimilar ciertos métodos del régimen pedagógico norteamericano, olvidando que su eficiencia está condicionada por el cumplimiento de todo un sistema, y que, de tomar tan solo una parte de él, era improbable un rendimiento satisfactorio. Me refiero a las pruebas objetivas. ¿Qué ejercicio mental realiza el alumno que responde: El autor de la Galatea se llamó........; La batalla de Warterloo se realizó el.......; Los ríos de Piura son........? ? ese alumno pierde toda facilidad para relacionar, para coordinar ideas y procurarles un orden, una secuencia y un relieve según el mérito e importancia de los hechos. Por eso, siempre será más útil el tipo de examen o de tabajo que deja al alumno en libertad de componer, esto es de seleccionar, porque así intervendrán además de la memoria, su sentido relacionante y su capacidad estética y fantástica. En gran parte, pues, experimentamos ahora las consecuencias de aquella infeliz reforma pedagógicailblioteca de Letras

Las líneas que canfeceden csone un Censayor para recoger todos los elementos que influyen en el aprendizaje de la lengua, pero según me parece, no descargan de responsabilidad a la orientación que domina nuestros planes escolares. La verdadera pregunta es, si en las condiciones actuales, agravadas por los hechos enumerados, ¿es la enseñanza de tipo gramatical la vía idónea para "hablar y escribir correctamente un idioma"?

Si el concepto de lenguaje alcanzado por la lingüística en la época contemporánea, realidad polar y móvil, enérgeia, creación e interpretación de la herencia cultural, lo confrontamos con la Gramática Normativa que se enseña en el Perú, código desespiritualizado de normas y excepciones, será de toda evidencia que, ni para conseguir un resultado práctico es hoy concebible técnicamente nuestro gramaticismo. Este, no sólo omite el aspecto individual, creador, activo, afectivo, fantástico, sino que se funda en un modelo fijo, que se supone correcto, desentendién- 
dose de toda la vivacidad y multiplicidad propias de la lengua. Sin el propósito de agotar este punto, quisiera reclamar la atención del auditorio hacia lo que sigue. La lengua, cualquier lengua, existe como "institución" de una colectividad dada. Pues bien, en la colectividad parlante compiten dos tendencias muy definidas : la primera, unitaria, cohesiva, y la otra diferenciadora. En virtud de la primera se producen las nivelaciones necesarias para salvar la diversidad regional, y de grados sociales. Un campesino no usa ni aproximadamente la misma lengua que un obrero de la capital, o que un minero; el lenguaje infantil acusa matices muy diferenciados frente a la lengua de los militares o de los empleados bancarios. Hay una lengua propia del ambiente eclesiástico y otra del universitario, como una del periodismo y otra de la literatura. La lengua civil, la lengua general, es un constante actuar y reaccionar de las tendencias unificadora y diferenciadora; pero es un constante proceso en virtud del ejercicio que de ellas hacen los parlantes y de los préstamos y acomodos que entre cada esfera profesional y social se suceden. La Gramática, queda en claro, no podrá jamás abarcar, ni comprender esta dinámica de la lengua, preocupada como está por la versión correcta, pese a que la perspectiva social del lenguaje destruye tal abstracción al ligarse a realidades concretas y variables. Tampoco se halla la gramática normativa en aptitud de explicar el proceso del lenguaje en el tiempo. EE profeson ab gramática normativa no se preocupará decesclarecem al hilurnnovlassozones por las que cantastes y llorastes han caído en desuso, y se limitará a sancionar que son formas incorrectas. Embarazo análogo ocurrirá, al tocar las formas de tratamiento, con el paso de vuestra merced a usted; o con la supervivencia de vido o vide en el lenguaje rústico. Finalmente, la gramática normativa ignora cuanto se refiere a la geografía lingüistica, a la repartición de las áreas de pronunciación o formas sintácticas en las diversas regiones, y se limitará a patrocinar la forma consagrada, sin dar explicación satisfactoria de los diversos grados de aceptación de los vocablos o usos; de su interpretación o correspondencia; de la aceptación de los cal$\cos$ o préstamos lingüísticos; del grado de difusión o valor tradicional de las fórmulas alternativas. No es pues poco lo que la Gramática Normativa deja fuera de sus intereses, y es sin duda, aquello que más falta le hará al estudiante: la lengua de su ambiente, del tiempo en que vive, de la región que habita, como un 
instrumento por el que se manifiestan sus actos más simples y los más complejos, la necasidad de la plegaria y su aspiración de vida cultural.

El proceso educativo consta de tres fases que equivalen a Ires grados de instrucción: primario, secundario, superior. El sentido unitario del proceso educativo no impide distinguirlos, y muy al conirario impone separar los objetivos propios de cada ciclo. Nada justifica por eso que el alumno deba repetir en la escuela, el colegio y la universidad, que el adverbio es una parte invariable de la oración, que el artículo es determinado e indeterminado, y que el complemento directo es el objeto o persona que recibe la acción inmediata del verbo. Que el estudiante memorice las verdades gramaticales, ¿lo ayudará a emplear con más habilidad su idioma? No. Tampoco lo ayudará el terrorismo de ese sistema infecundo que es el percentil ortográfico, el cual por desgracia aún tiene arraigo en el colegio y la Universidad. En lo que respecta a la enseñanza del español en la escuela primaria, no será difícil demostrar que la escasa capacidad abstractiva del niño, condena a la inutilidad cualquier esfuerzo clasificatorio de categorias o funciones del lenguaje. En cambio, el aprovechamiento justo de la teoría del signo lingǘstico, del valor entre significante y significado, entre lenquaje y mundo de los obietos, ofrecerá al profesor una perspectiva acertada, desde la que estará en condiciones de lograr: a) el refuerzo del espíritu comunicativo, y consecuentemente, el predominio de la gendenciániveladora des la lengua. Así desaparecerán los términos cuyo valor se reduce a la esfera familiar del infante, los usos regionales, los defectos de pronunciación. Es decir, el niño comprenderá que en lugar de pronunciar sabo, dijiera, conviene decir se, dijera, porque así coincide con el maestro y sus compañeros y nadie sonríe ante su charla; que en lugar de chapalo, o prestameló, tiene más acogida si pronuncia zapato o préstamelo; y descubrirá asímismo que ya no debe llamar al perro uauau, ni al caramelo calaca, ni al tambor luntún. b). La ampliación del vocabulario ayudará al niño en su progreso psicológico hacia la conquista de la realidad; los nombres serán el medio a través del cual el pequeño hablante se irá apoderando del mundo. Nivelación idiomática e incremento del vocabulario, ambas tareas conjugadas no por la obsesión de lo correcto sino de lo ejemplar, de la apropiado, traerán en la escuela primaria un progreso indudable en el afianzamiento del manejo de la len- 
gua. Y nada, nada de eso es gramática. Eso es, aunque asombre, educación lingüística, desarrollo del sentimiento lingüístico del hablante.

Menos fácil será precisar el objeto de la enseñanza de la lengua en la escuela secundaria. Hay todavía en este estadio una división nociva de la fase gramatical y la literaria. La enseñanza de lengua y literatura simultáneamente debe ser el ideal por lograr en esta etapa, pues sólo así cobrarán realidad los conceptos de lengua y habla, de creación y tradición. En, este punto conviene recordar un pensamiento de Bally acerca del método francés de hace ya varias décadas. De acentuarse la enseñanza de la literatura, en tanto historia literaria, menos será lo que se consiga en el interés del alumno, decía Bally. La historia literaria, de no responder a una selección indispensable, insistirá en trasladar la atención y la sensibilidad del estudiante del presente al pasado; a un pasado que incluso no entiende, 0 que, lo que es peor, le resulta grotesco o ridículo. La enseñanza de la literatura le parecerá entonces vacua, inútil, decorativa; no porque en realidad sea así, sino porque hay un profundo desacuerdo entre los ideales del adolescente y el desarraigo histórico que suponen las obras del pretérito. Por lo demás, el alumno no entenderá en qué medida el lenguaje estilizado, artificioso y convencional, que se achaca precipifadameinté a las letras de otra fiempo, podrá servirle en algo más que las categorías gramaticales y formas de la conjugación, que ya por la época en qués éstudia literatura comienzan a desvanecerse en su memoria.

Sería de provecho, en cambio, que en la enseñanza de lengua en la escuela secundaria, se atendiera a la diversidad de los impulsos expresivos que el hablante satisface con el lenguaje. En verdad, se trata de distintos instrumentos lingüísticos, que pueden clasificarse mediante dos series de oposiciones propuestas por Devoto: "por un lado la exigencia de la formulación precisa, atenta, y por otro de la formulación imprecisa o instintiva; por un lado la insistencia en la individualidad familiar o nacional de la expresión, y por otro la tendencia a disolver la personalidad individual - nacional frente a la necesidad impersonal y supronacional de hacerse entender. Existen así en nuestra cotidiana experiencia de hombres que hablamos y escribimos, una lengua literaria, una lengua coloquial, una lengua expresiva y una técnica. Encuadra- 
da así, la lengua literaria mantiene intacto el prestigio que le viene del hecho de ser la fuente principal para el estudio, pero debe admitir la existencia de otros aspectos, o fases".

Dicha lengua literaria presupone un apego a la tradición, una presencia activa de elementos racionales, y una atención intensa por lo que ésa ofrece y por lo nuevo que es necesario crear. "La lengua literaria colectiva se distingue de los otros tipos de lengua por tener un algo de elevado respecto de la lengua coloquial, y un algo de más personal frente a la lengua de la técnica". La lengua coloquial es una noción opuesta a la lengua literaria; en ella priva la trivialidad, el carácter genérico; abunda en palabras como este, cosa, cuestión; en perífrasis con hacer, dar, y en cierto modo su pobreza, que tal es su caudal comparado con la riqueza de la lengua literaria, se explica por el necesario relajamiento psicológico en la actividad humana. La Lengua expresiva se distingue de las anteriores por su exigencia fundamental de factores afectivos, y por la exténsión del ámbito en el cual goza de validez. Mientras la Lengua técnica posee como característica esencial su voluntad de superar los límites fijados por la inteligibilidad. Reduce o elimina todo matiz de sentimiento; simplifica al máximo su estructura, y tiende $a$ uniformarse en un sistema fácilmente reconocible. Un extremo de la lengua técnica es la simbología matemática:

La importancia de cada lengua depende de la circunstancia, de la condición Qeb hablante, de sus intereses; de la finalidad del hablar, de la época, etc. Los cuatro tipos o aspectos de la lengua no son compartimientos cerrados, son por el contrario focos de realizaciones lingüísticas que pueden influirse recíprocamente.

Presentar en la enseñanza de la lengua los aspectos enumerados, significará ofrecer a la atención del alumno una realidad que no le será indiferente, porque en su variedad y en su dinámica descubrirá el comienzo de una identidad que lo llevará al lenguaje como fenómeno integral.

Desde otro punto de vista, habría que criticar la costumbre de iniciar la enseñanza de la lengua partiendo de las clasificaciones tradicionales, que para otros fines poseen valor, pero que en el objetivo didáctico entorpecen y fraccionan la unidad de sentido. Muy de lamentar, porque carece de todo asidero teórico, 
es la castumbre de reducir la lengua a la enumeración morfológi$\mathrm{ca}$, olvidando con este sistema que las palabras no poseen un valor exclusivo, una única función en la realidad lingüística, hecho que sume al estudiante en el mayor de los desconciertos, pues reduce la riqueza de la lengua al esquematismo de la clasificación. Obsérvese en la serie que sigue cómo varía la función del vocablo bajo: hombre bajo, hablar bajo, condiclón bajo condición, el bajo se la robó, ¿bajo yo o él?, ¡bajo!, palabra que ha desempeñado sucesivamente funciones de adjetivo, adverbio, conjunción, sustantivo, verbo e interjección. No puede ignorarse tampoco el influjo decisivo de los morfemas, o el valor de las formas de relieve, o del orden de las palabras en la oración. Como de otra parte resulta innegable que una serie de términos carecen de valor semántico y sirven únicamente como partículas relacionantes; escúchese : abedecerá de tarde en tarde, espiaba por de entre los árboles. Morfológicarnente nada valará analizar locuciones del tipo "un ojo de la cara", o "buena como manda dios". Nada, ninguna novedad hay en cuanto aquí sostengo; ya Andrés Bello al ocuparse de la clasificación ordinaria se preguntaba: "¿Qué diríamos del que en un tratado de Historia Natural dividiese los animales en cuadrúpedos, aves, caballos, perros, áquilas y palomas?", y proponía atender a los "oficios" de los elementos idiomáticos, a las "funciones"; cambiolen lolinea dechnina đúe tesraldrá en la Filologia Hispánica una modermidad sorprendenter por eso es aconsejable que la enseñanza se coloque en el plano de los valores internos y procure determinar los verdaderos mecanismos de la lengua, como lo intenta Galichet al partir de las especies nominal y verbal, si bien este ensayo presupone distinguir nítidamente, a priori, entre la realidad ontológica y la realidad del lenguaje. Coseriu ha dicho con justicia que "La morfología y la sintaxis no existen antes de la definición formal mediante la que esos conceptos se estructuran; que ellos no son realidades del hablar, sino esquemas de aquel hablar sobre el hablar que es la gramática, es decir, esquemas de un metalenguaje". Y esta es una evidencia que no debe ignorarse, y su conclusión muy sencilla: enseñemos Lenguaje (1).

(1) Muy significotivamente, con ese nombre: Lenguaje, Lima, 1953, publicó luis Jeime Ciemeros un curso secundario que, sin embargo, no alcanzó 
Con lo dicho basta para fundar la enseñanza de la lengua en la Secundaria, bajo la inspiración del título de un hermoso libro de Bally: El Lenguaje y la Vida; para impedir que Lengua y Literatura sean asignaturas independientes; y para que la comprensión de lo leído y los ejercicios sean materia de meditación sintáctica, observando los matices y desajustes entre la forma gramatical y la psicológica, entre ló racional y lo emotivo.

En el tercer período, o sea en el nivel universitario, no puede admitirse que la finalidad del estudio de la lengua sea la misma que en la secundaria. Nunca será bastante si se insiste en desterrar de la Universidad procedimientos empíricos como el ya citado percentil ortográfico, o la clasificación morfológica. En principio, asiste el derecho de pensar que, en la Universidad, como en ninguno de los ciclos precedentes, se debe destacar la relación indisoluble entre Lengua y Cultura. No sólo contemplar y examinar la lengua como una determinada forma cultural, sino acercarse a través de ella, como sugiere Rohlfs, a los temas parciales de la historia cultural y de la historia de la civilización. La enseñanza universitaria de la lengua no debería, por ende, encasillarse en un programa de trabajo fijo, igual para cada año. Debería variar en cada período académico y, partiendo de uno o varios temas concretos, incitar al estudiante, futuro investigador o docente, hacia lo comprensión total del lenguaje, pues no de otra forma se manifiesta la teoría del sistema de la lengua. Es muy" posigle que cen este Givel désenseñanza, se obtenga provecho espléndido de atender sucesivamente a una es. tilística de la lengua, primero, y a una estilística del habla, después. Es indudable que, al trabajar sobre un texto popular, el aspecto verbal revelará su vigencia y hará casi desaparecer los conceptos de modo y tiempo. Y sorpresa análoga ocurrirá si en la novela costumbrista se observa la función diminutiva, con lo que se desvanecerá la ecuación diminutivo = pequeño, para colocarse en primer término la relación diminutivo = valor emocional, fantástico, afectivo.

entre nosotros la difusión que por su calidad merece. La lobor doçente de Ciszeros ya da frutos en el Seminario de Filologio Española del Instituto Riva Agüero, en la Facultad de Letras de la Universidad Católica y en la Escuela Normal Superior Guzmón y Valle. 
El estudio del habla tendrá que incidir en los temas de esti10. La lectura del Cíd, del diálogo de la Lengua, de los Comentarios Reales, permitirá conocer el valor estético-expresivo de dichos monumentos, pero podría servir para la provechosa apreciación diacrónica de ciertos desarrollos; pr. ej. el del epíteto, el ideal de naturalidad o el de artificio, el empleo del acusativo de relación; - los tópicos retóricos, las metáforas, etc., del modo como Curtius los trata en su Literatura Europea y Edad Media Latina.

En la enseñanza universitaria no se debe perder de vista los carriles que ofrece la ciencia del lenguaje. Por eso, así como sugerimos un sistema de labores apoyado en la distinción lenguahabla, diacronía-sincronía, proponemos que junto a la apreciación de los valores individuales se analice el aspecto social de la lengua y su vínculo con la nación, camino por el que tam preciosos frutos ha logrado la ciencia, entre los que se podrían anotar Lengua y Cultura de Francia de Vossler, a la Historia de la Lengua Española de Lapesa, o el Esquisse de la Langue Latine de Meillet.

En su vínculo con la cultura y la civilización (piénsese en los estudios de "Palabras y Cosas" y el aporte que éstos pueden brindar a la Antropología y a la Historia, especialmente en un país bilingüe como el Perú; $O$ piénsese en el interés de los topónimos como testimonio de un influjo sustratístico que puede aclarar la distribución idemơtáficon eneel Perúaprehispánico, y cooperar en el progreso del conocimiento geográfico), así como en el vínculo con la historia liferaria y estética, y con el desarrollo de los rasgos característicos de la nacionalidad, la lengua se mostrará al estudiante $\mathrm{y}$ al estudioso en la plenitud de su imagen: dinámica, polar, plena de historia y de espíritu. La enseñanza universitaria sería fecunda si difundiera e instruyera en cuanto hasta la fecha se ha trabajado en este campo, y si al mismo tiempo formara a quienes en el futuro puedan contribuir a prolongar y profundizar dichas labores. No se dirá entonces que el estudio de la Lengua es inútil y absurdo, que está de espaldas a la sociedad; y no se le confundirá con la charlatanería hueca y cursi de los filólogos silvestres, quienes creen que hacer labor en beneficio del país consiste en el ejercicio retórico de términos como patria, peruanidad, nacionalidad, si están huérfanos del conocimiento técnico indispensable que exigen las labores concretas, y de la orientación fundamental que decidirá la suerte del propósito. 
Al llegar a este punto, hemos recorrido suficiente camino. Fué menester primero ganar una idea de los estudios realizados en torno del lenguaje a lo largo de la historia, para llegar a la comprensión de cuanto hoy conoce la ciencia acerca de dicho fenómeno. Luego, fijada la idea del objeto que ocupa a la lingüística y de los métodos de trabajo de la ciencia, hemos confrontado lo que se hace en la enseñanza del español en nuestro país, con lo que, a tenor del estado actual de la lingüística, convendría realizar en beneficio de la enseñanza y de los estudiantes.

La sugerencia propuesta para insistir en un ordenamiento de la enseñanza del español, en tres ciclos fundados en los principios de : Nivelación Idiomática, Lengua y Vida, y Lengua y Cultura, se apoya a su vez en la aceptación previa y sin recortes de la imagen que la lingüística contemporánea ofrece del lenguaje. Sólo entendido éste en cuanto actividad espiritual, en tanto enérgeia, en tanto reelaboración de las tradiciones comunitarias, como dinámica entre individuo y sociedad, podrá avanzarse hasta un método educativo que supere el frustrado sistema memorístico y proponga el conocimiento activo del idioma. Sólo así superaremos el "gramaticismo" y la "gramatiquería"; y sólo así conseguiremos salvar los riesgos del "logicismo" y del "antilogicismo".

La Universidad, pese a los ultrajes que le han inferido los representantes del Congreso Nacional y un cierto sector interesado de la prensa limeña, Ciuega un Crol décisivo en la vida cultural del pásig e pejercen eplore buena sarte del Magisterio Nacional el influjo que todo egresado reconoce a su antigua Alma Mater. Ante el problema de la lengua, le toca a la Universidad reformarse y reformar. Ningún campo del conocimiento más identificado que el lenguaje con la finalidad humanística de esta Facultad, y ninguno más humano. Cuando el hablante expresa una idea, cuando manifiesta una opinión, asigna a los diversos elementos de que se sirve un valor determinado en el orden del mundo, tal como se lo representa y explica su mentalidad social. De donde proviene que la palabra proferida es, en un sentido lato, la re-creación del mundo, vale decir, un acto de re-presentación cosmológica, sin que importe que sea perceptible antes en la poesía que en la prosa. En el lenguaje se revela el diálogo del hombre con el mundo y la época; a través de él, el hombre se define a cada instante con respecto a la realidad; y al penetrar, también por él, en una herencia cultural, ejerce su 
derecho a la libertad cada vez que recrea el legado de la tradición. Si son fines de la Universidad, la Cultura y el Hombre, el lenguaje es el medio de realización de esos fines. Promover el estudio, la investigación, la discusión sobre el problema de la lengua en el Perú, es pues, tarea que le compete a la Universidad, y que dentro de San Marcos incumbe a la Facultad de Letras. La Faculiad que hoy acoge a sus nuevos alumnos posee una glo. riosa tradición reformista. Reformista en la ley, en la forma, y reformista en la esencia, en la estructura. Por eso Sr. Decano, Señores Profesores, me permito sugerir la conveniencia de un Symposium, auspiciado por esta Facultad, para que se contemplen los problemas que apenas ha podido esbozar este discurso, y para que, con sus conclusiones, se facilite la orientación de que hoy carece nuestro sistema pedagógico.

Hay otros aspectos que conviene tener en consideración si se desea remover las condiciones vigentes. El Profesor egresado de la Facultad de Educación como especialista en Castellano y Literatura, 0 el Doctor en Letras egresado de esta Facultad, están desprovistos de todo medio de protección que les garantice el trabajo en la disciplina en que se han preparado. Es frecuente que el que estudió Literafura enseñe Geografía, Educación Cívica o Historia Universal, y que, consecuentemente, quienes estudiaron Geografía, Historia Universcil a Psicologíq enseñen Español. La situación es compleja. El profespr acepta la anomalía por necesidad económica: "el Ministerio, probablemente, "por falta de organización con criterio técnico. Pero en el momento presente, cuando el Ministro desea escuchar la opinión de la Universidad sobre el problema general de la enseñanza secundaria, no sería insensato que San Marcos intercediera en favor de sus antiguos alumnos, y en provecho de la educación nacional. No menos satisfactorio sería que la Facultad de Letras, previo convenio con la Facultad de Educación y el Ministerio del Ramo, gestionara la paridad pedagógica y legal entre los títulos otorgados por nuestra Facultad y los concedidos por las demás instituciones similares. Será ese un aliciente mayor para quienes prosiguen la sección doctoral de Letras y un nuevo testimonio de la comunidad entre estudiantes, maestros y graduados.

Al empezar el nuevo Año Académico sin Ley Universitaria idónea y desprovistos de las rentas que el estado escamotea a la 
Universidad, esta invocación a meditar en el problema de la enseñanza del lenguaje, es al mismo tiempo una invitación a reafirmarnos en el destino cultural del hombre y en la misión social de la Universidad. Congregados en este acto solemne los integrantes de la Facultad de Letras de San Marcos, las palabras del Profesor que habla no desean sino interpretar la actitud optimista y afirmativa de quienes trabajamos armoniosamente en estas aulas $y$ estos patios. Porque si el lenguaje es, para el maestro y el alumno, tema de estudio y de comprensión vital, el lenguaje es también grito de fe, silencio de plegaria y confesión de Amor. Y si el amor es vía de conocimiento, la verdad, la que nos reúne ahora y nos acerca en el curso del año, esa verdad florece en la palabra.
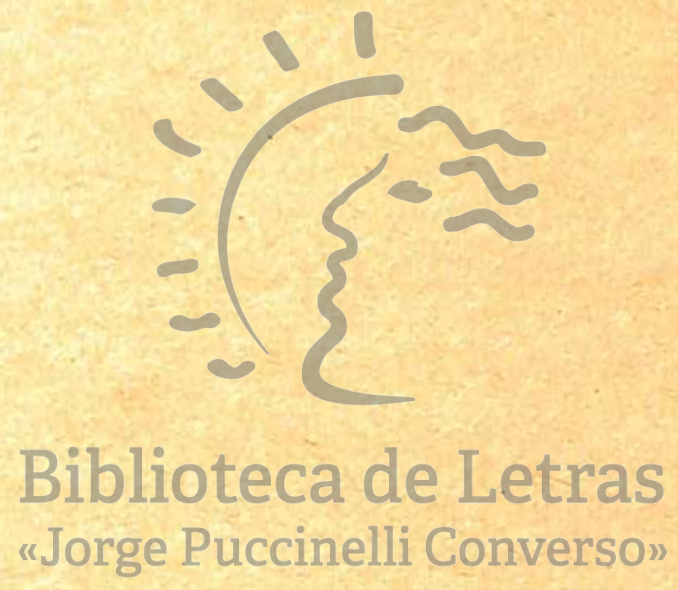